\title{
Review of the prevalence of risk factors of non- communicable diseases in Kashmir valley
}

\begin{abstract}
Background: Non-communicable diseases (NCD) are known threats to socio economic development not only in developing countries but worldwide. Urbanization and lifestyle changes happening rapidly around the globe including India have resulted in increased prevalence of NCD and Jammu \& Kashmir is no exception to this worldwide problem. The rising trend in NCD here warrants continuous surveillance and awareness amongst population. Estimating burden of modifiable risk factors contributing to NCD for intervention and prevention of NCDs is mandatory.
\end{abstract}

Method: This cross sectional study was carried out from June 2018 and continued till January 2019 in one of the blocks of District Budgam of Jammu \& Kashmir. A detailed predesigned health questionnaire was used to record the parameters like age, dwelling, marital status, socio economic status, history of dependencies \& duration, family and personal history of cardiovascular disease (CVD), hypertension, diabetes, behavioral history including lifestyle dependencies etc. of study participants, apparently healthy adults. Blood pressure, Random levels of blood sugar RBS and BMI of participant was recorded. The diagnosis of hypertension was done as per JNC 8 criteria and RBS levels $>140 \mathrm{mg} / \mathrm{dl}$ or patient on anti-diabetic medication was defined as diabetes. BMI of more than 23-29.9 and more than 30 was defined as overweight and obesity respectively.

Results: Adults with mean age of $46.8 \pm 8.54$ in males and $40.3 \pm 16.15$ females with the similar proportion of males and females in different age groups was recorded with $19.8 \%$ populace in the age group of $25-34$ as compared to $4.3 \%$ population in the age group of 75 84.Smoking was significantly higher in males as compared to females $(\mathrm{p}<0.001)$ pointing towards gender predilection. $86.6 \%$ females were living a sedentary life as compared to $72.4 \%$ of males ( $p$ value $<0.001$ ) revealing gender as independent factor for sedentary life as females remain mostly confined to their homes. Health behaviors, physical inactivity and obesity, show statistically significant association with NCD factors like hypertension and diabetes in this study ( $<<0.002 p<0.023$ resp. table) In present study only $2.6 \%$ males and $5.7 \%$ females had their hypertension controlled $8 \%$ and $11.2 \%$ males and females respectively were not controlled.12\% of males and $10.8 \%$ of females were not aware and they were diagnosed hypertensive during study. Similarly for diabetes only $(1.7 \% \mathrm{~m} \&$ $3.2 \%$ f) were known diabetes with controlled blood sugar levels .However major chunk of the affected population were either uncontrolled $(3.2 \% \mathrm{~m} \& 4.7 \% \mathrm{f})$ or unaware $(9.6 \% \mathrm{~m} \&$ $7.0 \% \mathrm{f}$ ) of the disease.

Conclusion: The study conducted in the semi urban area of $\mathrm{J} \& \mathrm{~K}$ revealed that behavioral and biological cardio vascular risk factors are prevalent in the population. Awareness about these NCD is low. Physical inactivity and increasing BMI were the two important modifiable health risk behaviors associated with hypertension. Making common people aware about seeking health care for screening of these risk factors of NCD for detection of high risk group and implementation of evidence based management to reduce the mortality and morbidity related NCD is the need of the hour.

Keywords \& abbreviations: NCD, non communicable disease; RBS, random blood sugar; JNC 8 , joint national committee 8 , BMI, body mass index
Volume 9 Issue 2 - 202I

\author{
Nasreen Jan,' Rehana Kausar, ${ }^{2}$ Saleemur \\ Rehman ${ }^{3}$ \\ 'Department of Pharmacology, Kashmir University, India \\ ${ }^{2}$ \&K Health Services, Kashmir University, India \\ ${ }^{3}$ Kashmir University, India
}

Correspondence: Nasreen Jan, Department of Pharmacology, Kashmir University, India, Tel 9419017365,

Email nasreenchashoo@yahoo.co.in

Received: October 29, 2020 | Published: April 19, 2021

\section{Introduction}

Non-communicable diseases (NCDs) have been recognized as known threats to socio-economic development worlwide. ${ }^{1-3}$ In low and middle-income countries, where urbanization and lifestyle changes are happening at a rapid pace, they have emerged out as additional burden on healthcare system. ${ }^{4}$ In developing countries cardiovascular diseases (CVD) prevalence has reached to an alarming proportion ${ }^{5,6}$ which contributes to $23 \%$ and $30 \%$ of the total mortality in rural and urban population, respectively, in India. ${ }^{7-10}$ It is further on an increase in the state of Jammu and Kashmir like other community undergoing life style changes and the stress for the last 25 years due to disturbed situation in the state that has apparently contributed to increased prevalence. ${ }^{11}$ Besides bringing industrial, social and economical upliftment, urbanization has unfortunately increased unhealthy habits of consumption of high calorie foodstuffs, sedentary and stressful life and addictions in the community, thus adding more risk. ${ }^{12}$ These risk factors are measurable and modifiable therefore become the most important targets for cost effective intervention for prevention and control of CVD risk factors. ${ }^{13}$ Previous epidemiological studies have demonstrated rising trends of $\mathrm{NCD}^{11}$ which mandates the continuous surveillance for capturing the current trend. This article aims at estimating the present burden of the biological and behavioral risk factors contributing to NCD, to prioritize the health policies and programme for prevention of risk factors. The study was carried out 
in the adult population of the semi-urbanised area namely Chattergam of block B.K Pora in District Budgam.

\section{Material and methods}

After obtaining formal approval from the IEC of DHSK this cross sectional community based study was carried amongst the apparently healthy adult residents of the area Chattergam in the block BK Pora of District Budgam of Jammu and Kashmir state which is a semi urban region. It lies about $9 \mathrm{kms}$ towards east from district headquarters Budgam and $11 \mathrm{kms}$ from state capital Srinagar. Area has a population of 99812 as per 2011 census. On the basis of assumed prevalence of diabetes of $6.56 \%$ in the area sample size was calculated. Written informed consent was obtained from participants selected by random sampling method after explaining the purpose of study in detail in their own local language. Survey team comprising of health workers were trained before for carrying out the study which included brief introduction about NCD and the role of (both biological and behavioral) risk factors. Methods of recording anthropometry, Blood Pressure, estimation of Blood Sugar with glucometer were demonstrated in detail to enhance skills for using survey tools. A detailed predesigned health questionnaire including parameters like age, dwelling, marital status, socio economic status, history of dependencies their duration, family and personal history of CVD, hypertension, diabetes, behavioral history including lifestyle dependencies etc. was used for record. Three recordings of blood pressure were taken of each participant in a comfortable sitting posture. Average of the three readings was recorded as final reading and the diagnosis of hypertension was done as per JNC 8 criteria. Random levels of blood sugar of participants were estimated by glucometer and RBS levels $>140 \mathrm{mg} / \mathrm{dl}$ or patient on anti-diabetic medication was defined as diabetes. BMI of more than 23-29.9 and more than 30 was defined as overweight and obesity respectively. Survey was carried from June 2018 and continued till January 2019.

Statistical methods: Data compiled was entered in a spreadsheet (Microsoft Excel) and then exported to data editor of SPSS Version 20.0 (SPSS Inc., Chicago, Illinois, USA). Continuous variables were expressed as Mean $\pm \mathrm{SD}$ and categorical variables were summarized as frequencies and percentages. Graphically the data was presented by bar diagrams. Chi-square test or Fisher's exact test, whichever appropriate, was applied for comparison of categorical variables.A P-value of less than 0.05 was considered statistically significant. All $\mathrm{P}$-values were two tailed.

\section{Discussion}

In September 2011United Nations Summit declared NCDs as leading global public health problem. ${ }^{14}$ Non communicable diseases (NCDs) contribute to around 5.87 million (60\%) of all deaths in India, having a population of 1.3 billion approximately. ${ }^{15}$ Majority of global NCD related deaths are reported from developing countries like India which is undergoing an epidemiological health transition owing to rapid urbanization. ${ }^{16}$ In our region (J\&K) due to increased load of cardiac patients in the hospitals, studies regarding prevalence of various risk factors associated have been conducted from time to time. Changing trends in lifestyle and behavioral factors resulting in ever increasing number of CVD patients requires more comprehensive picture of the recognition and correlation of these behavioral practices with the prevalence of different risk factors for prevention and management of the disease effectively. With this objective in mind this study was conducted. In the present study the surveyed population comprised of adults with mean age of $46.8 \pm 8.54$ in males and $40.3 \pm 16.15$ females with the similar proportion of males and females in different age groups (Table 1).19.8\% populace in the age group of $25-34$ as compared to $4.3 \%$ population in the age group of 75-84 was recorded according to demography of region (Table 1). Health behavior and life style of the surveyed population revealed that smoking was significantly higher in males as compared to females ( $p$ $<0.001$ Table 2) pointing towards gender predilection an important determinant of tobacco consumption behavior in the semi urban locale of JK and is being consumed primarily by males as reported by other study as well. ${ }^{17} 86.6 \%$ females were living a sedentary life as compared to $72.4 \%$ of males ( $p$ value $<0.001$ Table 2 ) revealing gender as independent factor for sedentary life as females remain mostly confined to their homes like other regions of country. Similarly obesity and overweight population was significantly higher in females ( $<<0.001$ Table 2). Health behaviors, physical inactivity and obesity, show statistically significant association with NCD factors like hypertension and diabetes in this study $(\mathrm{p}<0.002 \mathrm{p}<0.023$ resp. Table $3 \&$ Table 4.) (Figure 1) as is reported by other epidemiological studies also. Association of behavioral risk factors with hypertension and diabetes are independent risk factors for these NCDs. However, its association with tobacco consumption is not consistent. ${ }^{18,19}$ These observations of an independent and significant association of physical inactivity and increasing BMI have important implications from the perspective of public health intervention for prevention of these NCD.

Table I Age and gender wise distribution of surveyed population

\begin{tabular}{lllllll}
\hline \multirow{2}{*}{ Age $($ years) } & Male & \multicolumn{3}{c}{ Female } & Total \\
\cline { 2 - 7 } & No. & \%age & No. & \%age & No. & \%age \\
\hline $18-24$ & 94 & 14.5 & 131 & 17.7 & 225 & 16.2 \\
$25-34$ & 100 & 15.4 & 174 & 23.5 & 274 & 19.8 \\
$35-44$ & 104 & 16.0 & 156 & 21.1 & 260 & 18.7 \\
$45-54$ & 109 & 16.8 & 116 & 15.7 & 225 & 16.2 \\
$55-64$ & 85 & 13.1 & 80 & 10.8 & 165 & 11.9 \\
$65-74$ & 112 & 17.3 & 58 & 7.8 & 170 & 12.3 \\
$75-84$ & 40 & 6.2 & 19 & 2.6 & 59 & 4.3 \\
$>85$ & 4 & 0.6 & 5 & 0.7 & 9 & 0.6 \\
Total & 648 & 100 & 739 & 100 & 1387 & 100 \\
Mean \pm SD & $46.8 \pm 18.54$ & & $40.3 \pm 16.15$ & & $41.7 \pm 17.03$ & \\
\hline
\end{tabular}

1387 randomly selected subjects were surveyed to estimate the prevalence of NCD risk factors. Mean age of population was $41.7 \pm 17.03$ years of which 648 were men and 739 women 
Table 2 Gender wise distribution of NCD risk factors

\begin{tabular}{|c|c|c|c|c|c|}
\hline \multirow{2}{*}{ Risk factor } & \multicolumn{2}{|c|}{ Male $[n=648]$} & \multicolumn{2}{|c|}{ Female $[n=739]$} & \multirow{2}{*}{ P-value } \\
\hline & No. & \%age & No. & \%age & \\
\hline Tabacco smokers & 300 & 46.3 & 21 & 2.8 & $<0.00 I^{*}$ \\
\hline Sedentary lifestyle & 469 & 72.4 & 640 & 86.6 & $<0.00 I^{*}$ \\
\hline Over weight and obese $(\mathrm{BMI} \geq 23)$ & 378 & 58.3 & 579 & 78.3 & $<0.00 I^{*}$ \\
\hline Total no of known Hypertension & 69 & 10.6 & 125 & 16.9 & $0.002^{*}$ \\
\hline Hypertension Diagnosed and controlled & 17 & 2.6 & 42 & 5.7 & $0.005^{*}$ \\
\hline Hypertension Diagnosed, but not controlled & 52 & 8.0 & 83 & 11.2 & $0.044^{*}$ \\
\hline Newly detected HTN & 78 & 12.0 & 80 & 10.8 & 0.478 \\
\hline Total no of known DM & 32 & 4.9 & 59 & 8.0 & $0.023^{*}$ \\
\hline known Diabetes on medicine controlled B/S below I 40 & 11 & 1.7 & 24 & 3.2 & 0.067 \\
\hline Known Diabetes on medicine but B/S not controlled Above 140 & 21 & 3.2 & 35 & 4.7 & 0.158 \\
\hline Newly detected DM & 62 & 9.6 & 52 & 7.0 & 0.086 \\
\hline
\end{tabular}

*Statistically Significant Difference (P-value<0.05)

The prevalence of diagnosed controlled as well as uncontrolled was significant high in females $(p$ value $<0.005,<0.044$ ). Similarly prevalence of diabetes controlled as well as uncontrolled was significantly higher in females ( $p$ value $<0.023$ ). Behavioral risk factors tobacco smoking and physical inactivity was significantly higher in males ( $\mathrm{p}$ value $<0.00 \mathrm{I},<0.00 \mathrm{I}$ respectively)

Table 3 Showing Association of various risk factors with hypertension in study population

\begin{tabular}{|c|c|c|c|c|c|}
\hline \multirow{2}{*}{ Risk factor } & \multicolumn{2}{|c|}{ Hypertensive [n=456] } & \multicolumn{2}{|c|}{ Non-hypertensive [n=93I] } & \multirow{2}{*}{ P-value } \\
\hline & No. & \%age & No. & \%age & \\
\hline Smoking & 112 & 24.6 & 209 & 22.4 & 0.381 \\
\hline Sedentary lifestyle & 382 & 83.8 & 727 & 78.1 & $0.013^{*}$ \\
\hline Over weight and obese $(\mathrm{BMI} \geq 23)$ & 337 & 73.9 & 620 & 66.6 & $0.006 *$ \\
\hline
\end{tabular}

*Statistically Significant (P-value<0.05)

Sedentary life style and increased BMI had a significant association correlation with hypertension ( $p$ value $<0.013,<0.006$ resp).Strong association of smoking was also found with smoking ( $\mathrm{p}$ value $<0.38 \mathrm{I}$ )

Table 4 Showing association correlation of various risk factors with diabetes in study population

\begin{tabular}{|c|c|c|c|c|c|}
\hline \multirow{2}{*}{ Risk factor } & \multicolumn{2}{|c|}{ Diabetic [n=205] } & \multicolumn{2}{|c|}{ Non-diabetic $[n=I \mid 82]$} & \multirow{2}{*}{ P-value } \\
\hline & No. & \%age & No. & \%age & \\
\hline Smoking & 52 & 25.4 & 269 & 22.8 & 0.413 \\
\hline Sedentary lifestyle & 184 & 89.8 & 925 & 78.3 & $<0.00 I^{*}$ \\
\hline Over weight and obese (BMI $\geq 23$ ) & 160 & 78.0 & 797 & 67.4 & $0.002 *$ \\
\hline
\end{tabular}

*Statistically Significant $(\mathrm{P}-\mathrm{value}<0.05)$ 


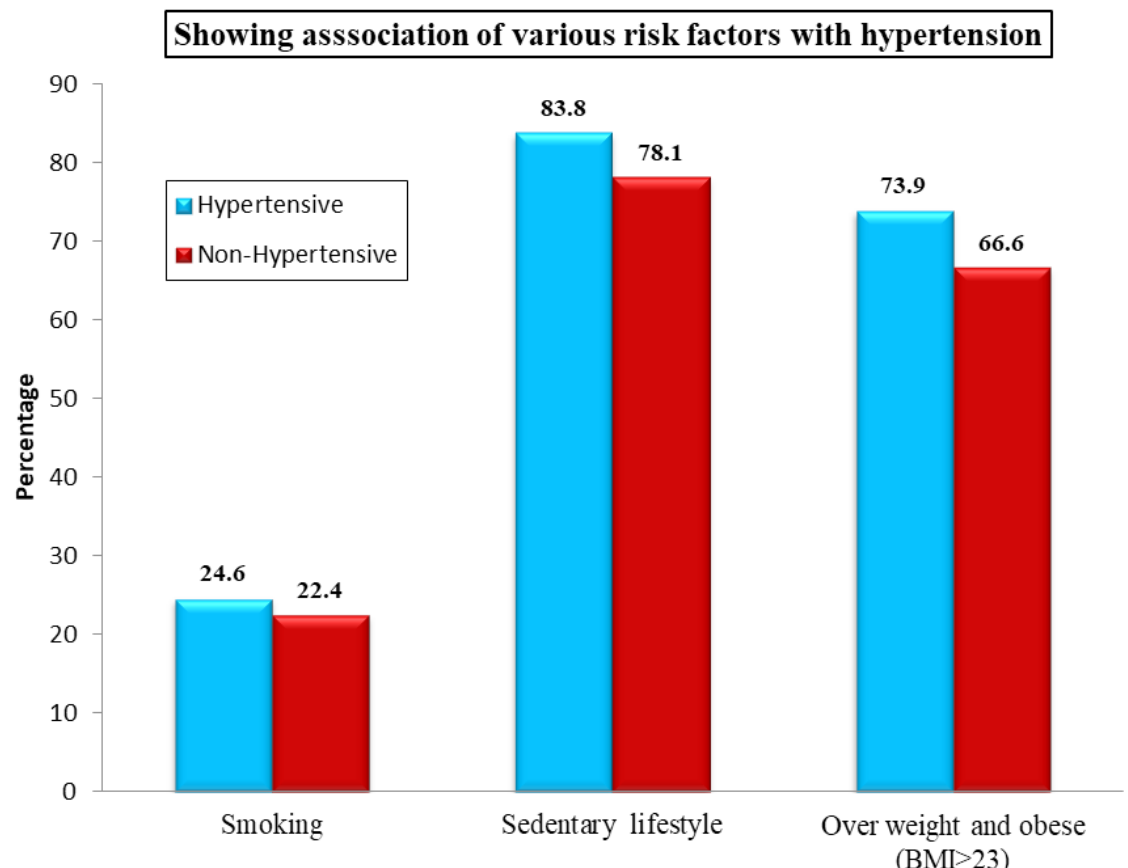

Figure I Associate of risk factors \& hypertension.

Physical inactivity and obesity show significant association with diabetes also ( $p$ value $<0.001,<0.002$ resp) In present study only $2.6 \%$ males and $5.7 \%$ females had their hypertension controlled $8 \%$ and $11.2 \%$ males and females respectively were not controlled. $12 \%$ of males and $10.8 \%$ of females were not aware and they were diagnosed hypertensive during study. Similarly for diabetes only $(1.7 \% \mathrm{~m} \& 3.2 \% \mathrm{f})$ were known diabetes with controlled blood sugar levels. However major chunk of the affected population were either uncontrolled $(3.2 \% \mathrm{~m} \& 4.7 \% \mathrm{f})$ or unaware $(9.6 \% \mathrm{~m} \& 7.0 \%$ f) of the disease. This shows very small number of patients having hypertension and diabetes have controlled blood pressure and blood glucose and large proportion of population are either not aware of or are having uncontrolled levels. This remains the major challenge in reducing the mortality and morbidity related to CVD. This lack of awareness and compliance to medication needs to be addressed by identifying and addressing the barriers in improving early detection, compliance and control of diseases.

\section{Conclusion}

The study conducted in the semi urban area of J\&K to know prevalence of NCD risk factors and their determinants revealed that behavioral and biological cardio vascular risk factors are prevalent in the population. Awareness about these NCD is low. Physical inactivity and increasing BMI were the two important modifiable health risk behaviors associated with hypertension mandating the urgent need for launching aggressive community health education to create awareness about health risk behaviors and their health consequences. There is a need to create the awareness about seeking health care for screening of these risk factors of NCD for detection of high risk group and implementation of evidence based management to reduce the increasing trend of NCD risks factors and thereof reducing the mortality and morbidity related to them.

\section{Acknowledgments}

None.

\section{Conflicts of interest}

The authors declare that there is no conflict of interest.

\section{References}

1. Murray CJ, Theo Vos, Rafael Lozano, et al. Disability-adjusted life years (DALYs) for 291 diseases and injuries in 21 regions, 1990-2010: a systematic analysis for the Global Burden of Disease Study 2010. Lancet. 2013;380:2197-2223.

2. World Health Organization. Global status report on non-communicable diseases 2014. 2014.

3. Thomas J Bollyky, Tara Templin, Matthew Cohen, et al. Lower-income countries that face the most rapid shift in non communicable disease burden are also the least prepared. Health Aff. 2017;36:1866-1875.

4. Nelia P Steyn, Zandile J McHiza. Obesity and the nutrition transition in Sub-Saharan Africa. Ann N Y Acad S. 2014;11:88-101.

5. Reddy KS, Yusuf S. Emerging epidemic of cardiovascular disease in developing countries. Circulation. 1998;97:596-601.

6. World Health Organization. Non-communicable Diseases in South-East Asia Region. A Profile. World Health Organization; New Delhi. 2002.

7. Ministry of Home Affairs: Report on Causes of Death in India 2001-2003. Office of the Registrar General, New Delhi, India. 2003.

8. Ministry of Health and Family Welfare, Government of India; New Delhi: Burden of Disease in India, Background Papers for the National Commission on Macroeconomics. 2005.

9. Gupta R. Burden of coronary heart disease in India. Indian Heart J. 2005;57:632-638.

10. Indian Council of Medical Research; New Delhi: WHO Study on assessment of burden of NCD. Report of the ICMR. 2006.

11. Saleem-ur Rehman, Kadri SM, Rehana Kausar, et al. Twin load of hypertension and diabetes amongst adults: community based study from Jammu and Kashmir, India. IJRMS. 2014;2(1). 
12. Jyotdeep K Raina, Minakashee Sharma, Surbhi Sethi, et al. A pilot study on recognition and prevalence of risk factors for cardiovascular disease in north Indian populace of Jammu \& kashmir. J Hum Ecol. 2018;62(13):47-57.

13. Gupta R, Joshi P, Mohan V, et al. Epidemiology and causation of coronary heart disease and stroke in India. Heart. 2008;94:16-26.

14. Alafia Samuels T, John Kirton, Jenilee Guebert. Monitoring compliance with high-level commitments in health: the case of the CARICOM Summit on chronic non-communicable diseases. Bull World Health Organ. 2014;92:270-276.

15. World health organization. Non communicable diseases in the South-East Asia region: Situation and response 2011. New Delhi, India. World health organization regional office for South-East Asia. 2011
16. Chakma JK, Gupta S. Lifestyle and non-communicable diseases: A double edged sword for future India. Indian J Comm Health. 2014;26:325-332.

17. Prakash Chand Negi, Raman Chauhan, Vivek Rana, et al. Epidemiological study of non-communicable diseases (NCD) risk factors in tribal district of Kinnaur, HP: A cross-sectional study. Indian Heart J. 2016;5:68.

18. Sampatti Sambhaji Todkar, Venktesh V Gujarathi, Vinay S Tapare. Period prevalence and sociodemographic factors of hypertension in rural Maharashtra: a cross sectional study. Indian J Community Med. 2009;34:183-187.

19. Sushil K Bansal, Vartika Saxena, Sunil D Kandpal, et al. Prevalence of hypertension and hypertension risk factors in rural Indian community: a prospective door to door study. J Cardiovasc Dis Res. 2012;3:117-123. 